\title{
Risk Factors for Neonatal Death in Female Workers Mothers in Indonesia
}

\author{
Ratna Dwi Wulandari ${ }^{1}$, Agung Dwi Laksono ${ }^{2}$, Astridya Paramita ${ }^{3}$, Pramita Andarwati ${ }^{3}$, Naillul Izza ${ }^{3}$ \\ ${ }^{1}$ Lecturer, Faculty of Public Health, Universitas Airlangga Surabaya, Indonesia, ${ }^{2}$ Researcher, National Institute \\ of Health Research and Development, The Ministry of Health, The Republic of Indonesia, Jakarta, Indonesia, \\ ${ }^{3}$ Researcher, Functional Unit of Health Technology Innovation, The Republic of Indonesia, Jakarta, Indonesia.
}

\begin{abstract}
Female worker mothers have a greater risk of neonatal death during childbirth. The study aimed to analyze the risk factors for neonatal death among female worker mothers in Indonesia. The study used data of the 2017 Indonesia Demographic and Health Survey. With stratification and multistage random sampling, 18,061 female worker mothers aged 15-49 years old with live births in the last 5 years were sampled. The final analyzed using a binary logistic regression test. The results of the study found that female worker mothers with the wealth status of the poorer category had 0.738 times the probability of experiencing neonatal death compared to the poorest. Female worker mothers with wealth status in the middle category have a probability of 0.702 times compared to the poorest to experience neonatal death. Meanwhile, the richest female worker mothers had a probability of 0.662 times compared to the poorest to experience neonatal death. Meanwhile, female worker mothers who made ANC visits $\geq 4$ times had a probability of 0.331 times compared to female worker mothers who made ANC visits $<4$ times. It could be concluded that there were 2 factors which are the risk factors for neonatal death among female worker mothers in Indonesia, namely poverty and ANC visits $<4$ times.
\end{abstract}

Keywords: Neonatal death,maternal health, female worker, risk factor.

\section{Introduction}

The third goal of the Sustainable Development Goals, which was formulated and agreed upon to be achieved by all countries without exception, is to ensure a healthy life and support the welfare of all for all ages. One of the targets set to achieve this goal is to reduce the neonatal mortality rate to at least less than 12 per 1,000 births by $2030^{1}$.

Neonatal mortality is death that occurs before the baby is 28 days old. Neonatal Mortality Rate is the number of live births that died within the first 28 days of

\section{Corresponding Author:}

\section{Ratna Dwi Wulandari}

Faculty of Public Health, Universitas Airlangga

Surabaya, Indonesia, Campus C Mulyosari Surabaya, Indonesia

e-mail: ratna-d-w@fkm.unair.ac.id life, per 1,000 live births in a given year. Based on the age group of infants, neonatal mortality is categorized into two, namely early neonatal mortality and late neonatal death. Early neonatal mortality is the death of a live-born baby within the first week of life or 7 days after birth, which is also called perinatal death (infants aged 0-7 days). Late neonatal mortality is the death of a live-born baby at the age of more than 7 days to 28 days, that is, the second to the fourth week of life. In general, neonatal mortality is caused by endogenous factors, namely factors that the child carries from birth, which is obtained from the parents at conception or during pregnancy, as well as conditions during and after delivery such as the occurrence of nosocomial infections from the ward or due to bleeding diseases in newborn baby $^{2}$.

Global data in 2018 shows that 2.5 million children die in their first month of life, of which around 7000 newborn deaths occur every day with about one-third dying on the day of birth and nearly three-quarters 
of them dying within the first week of life. Neonatal mortality decreases more slowly than mortality in children 1-59 months of age ${ }^{3}$. Meanwhile, Indonesia recorded a fairly high neonatal mortality rate. Analysis of the Indonesian Demographic and Health Survey in 2017 reports that the Neonatal Mortality Rate in Indonesia reaches 15 neonates per 1000 live births. This achievement is higher than the achievement recorded by countries in the region ${ }^{4}$.

Female workers are suspected of having a greater risk of experiencing neonatal death because of their dual duties to support daily family needs and pregnancy care. A previous study informed that female workers had a 1.52 times greater risk of experiencing neonatal death than non-female workers ${ }^{5}$.Meanwhile, another study informed that women who do not work are more likely to experience neonatal pulse 0.576 times compared to female workers ${ }^{6}$. Based on the background description, the study was aimed at analyzing the risk factors for neonatal death among female worker mothers in Indonesia.

\section{Materials and Method}

The study used data from the 2017 Indonesian Demographic Data Survey (IDHS) as analysis material. The 2017 IDHS sample was determined through stratification and multistage random sampling. The unit of analysis in this study was female worker mothers, 15 49 years old, who had given birth in the last 5 years. Several 18,061 respondents were sampled.

Neonatal death is death in the neonatal period or the first twenty-eight days of life. Other variables analyzed as independent variables were a place of residence, age groups, education level, wealth status, parity, antenatal care (ANC), complication during pregnancy, childbirth assistance, and place of delivery. Place of residence divided into urban and rural. Age is the respondent's last birthday. The education level is the last educational certificate the respondent has.

Wealth status was a wealth of respondents compiled based on the index of goods ownership quintile stated by the respondent. The five categories were the poorest (quintile 1), poorer (quintile 2), middle (quintile 3), richer (quintile 4), and richest (quintile 5). Parity is the number of living children a woman has ever born. In this study, parity was divided into two, namely primiparous ( $<2$ children), and multiparous ( $\geq 2$ children).

Complications during pregnancy were the respondent's acknowledgment of complications experienced during pregnancy until delivery. These problems consist of: prolonged labor, vaginal bleeding, fever, convulsions, baby in the wrong position, swollen limbs, faint, breathlessness, tiredness, and others ${ }^{4}$. Childbirth assistance was divided into two categories, namely non-health workers and health workers. Meanwhile, the place of delivery consists of nonhealthcare facilities and healthcare facilities.

Statistical analysis using chi-square was carried out to select the variables. Estimates were performed using binary logistic regression because of the nature of the dependent variable. All statistical analyses were carried out using SPSS 22 software.

\section{Results and Discussion}

The information in Table 1 shows that in both categories, neonatal death is dominated by female worker mothers who live in rural areas. The two categories of neonatal death were also dominated by female worker mothers in the 35-39 age group who had secondary education. Based on wealth status, the two categories of neonatal death were dominated by the poorest female worker mothers.

Table 1. Descriptive statistics of female worker mothers characteristics in Indonesia $(n=18,061)$

\begin{tabular}{|c|c|c|c|c|c|}
\hline \multirow{3}{*}{ Variables } & \multicolumn{4}{|c|}{ Neonatal Death } & \multirow{3}{*}{$\mathbf{P}$} \\
\hline & \multicolumn{2}{|c|}{ No } & \multicolumn{2}{|c|}{ Yes } & \\
\hline & $\mathrm{n}$ & $\%$ & $\mathbf{n}$ & $\%$ & \\
\hline \multicolumn{5}{|c|}{ Place of Residence } & 0.056 \\
\hline Urban & 8211 & $46.6 \%$ & 178 & $41.9 \%$ & \\
\hline Rural(ref.) & 9425 & $53.4 \%$ & 247 & $58.1 \%$ & \\
\hline
\end{tabular}




\begin{tabular}{|c|c|c|c|c|c|}
\hline \multirow{3}{*}{ Variables } & \multicolumn{4}{|c|}{ Neonatal Death } & \multirow{3}{*}{$\mathbf{P}$} \\
\hline & \multicolumn{2}{|c|}{ No } & \multicolumn{2}{|c|}{ Yes } & \\
\hline & $\mathbf{n}$ & $\%$ & $\mathbf{n}$ & $\%$ & \\
\hline \multicolumn{5}{|l|}{ Age groups } & 0.686 \\
\hline 15-19 уо. & 93 & $0.5 \%$ & 2 & $0.5 \%$ & \\
\hline 20-24 уо. & 1001 & $5.7 \%$ & 20 & $4.7 \%$ & \\
\hline $25-29$ yo & 2939 & $16.7 \%$ & 67 & $15.8 \%$ & \\
\hline 30-34 уо. & 4716 & $26.7 \%$ & 108 & $25.4 \%$ & \\
\hline 35-39 уо. & 5030 & $28.5 \%$ & 119 & $28.0 \%$ & \\
\hline 40-44 уо. & 3037 & $17.2 \%$ & 86 & $20.2 \%$ & \\
\hline 45-49 уо. (ref.) & 820 & $4.6 \%$ & 23 & $5.4 \%$ & \\
\hline \multicolumn{5}{|l|}{ Education level } & $* * *<0.001$ \\
\hline No education (ref.) & 556 & $3.2 \%$ & 21 & $4.9 \%$ & \\
\hline Primary & 5199 & $29.5 \%$ & 156 & $36.7 \%$ & \\
\hline Secondary & 8125 & $46.1 \%$ & 184 & $43.3 \%$ & \\
\hline Higher & 3756 & $21.3 \%$ & 64 & $15.1 \%$ & \\
\hline \multicolumn{5}{|l|}{ Wealth status } & $* * *<0.001$ \\
\hline Poorest (ref.) & 5358 & $30.4 \%$ & 177 & $41.6 \%$ & \\
\hline Poorer & 3045 & $17.3 \%$ & 67 & $15.8 \%$ & \\
\hline Middle & 2937 & $16.7 \%$ & 59 & $13.9 \%$ & \\
\hline Richer & 2987 & $16.9 \%$ & 65 & $15.3 \%$ & \\
\hline Richest & 3309 & $18.8 \%$ & 57 & $13.4 \%$ & \\
\hline \multicolumn{5}{|l|}{ Parity } & $* * *<0.001$ \\
\hline Primiparous & 2088 & $11.8 \%$ & 20 & $4.7 \%$ & \\
\hline Multiparous (ref.) & 15548 & $88.2 \%$ & 405 & $95.3 \%$ & \\
\hline \multicolumn{5}{|l|}{ ANC } & $* * *<0.001$ \\
\hline$<4$ times (ref.) & 11214 & $63.6 \%$ & 358 & $84.2 \%$ & \\
\hline$\geq 4$ times & 6422 & $36.4 \%$ & 67 & $15.8 \%$ & \\
\hline \multicolumn{5}{|c|}{ Complication during pregnancy } & 0.078 \\
\hline No & 5744 & $82.0 \%$ & 65 & $74.7 \%$ & \\
\hline Yes (ref.) & 1259 & $18.0 \%$ & 22 & $25.3 \%$ & \\
\hline \multicolumn{5}{|l|}{ Childbirth assistance } & $* * *<0.001$ \\
\hline Non-health worker (ref.) & 10305 & $58.4 \%$ & 318 & $74.8 \%$ & \\
\hline Health worker & 7331 & $41.6 \%$ & 107 & $25.2 \%$ & \\
\hline \multicolumn{5}{|l|}{ Place of delivery } & $* * *<0.001$ \\
\hline Non-Healthcare (ref.) & 11532 & $65.4 \%$ & 339 & $79.8 \%$ & \\
\hline Healthcare & 6104 & $34.6 \%$ & 86 & $20.2 \%$ & \\
\hline
\end{tabular}

Note: ${ }^{*} \mathrm{p}<0.05 ;{ }^{* *} \mathrm{p}<0.01 ;{ }^{* * *} \mathrm{p}<0.001$.

Table 1 shows that the two categories of neonatal death are also dominated by multiparous female worker mothers, and have incomplete ANC visits ( $<4$ times).
Meanwhile, based on complications during pregnancy, the two categories of neonatal death were dominated by female worker mothers who did not experience 
complications during pregnancy. The two categories of neonatal death are also dominated by female worker mothers who are accompanied by health workers during childbirth, and who do childbirth in non-healthcare.

Table 2 provides the results of the multivariate test with binary logistic regression. There are 6 variables included in the final stage of determining risk factors for neonatal death among female worker mothers in Indonesia. The results of the analysis found that 2 variables were proven as risk factors for neonatal death among female worker mothers in Indonesia.

Table 2. The result of binary logistic regression of the risk factors for neonatal death among female worker mothers in Indonesia $(n=18,061)$

\begin{tabular}{|c|c|c|c|c|}
\hline \multirow{3}{*}{ The Predictors } & \multicolumn{4}{|c|}{ The Neonatal Death } \\
\hline & \multirow{2}{*}{ Sig. } & \multirow{2}{*}{ OR } & \multicolumn{2}{|c|}{ CI $(95 \%)$} \\
\hline & & & Lower Bound & Upper Bound \\
\hline Education status: No education & - & - & - & - \\
\hline Education status: Primary & 0.798 & 0.941 & 0.589 & 1.502 \\
\hline Education status: Secondary & 0.607 & 0.882 & 0.545 & 1.425 \\
\hline Education status: Higher & 0.344 & 0.768 & 0.445 & 1.326 \\
\hline Wealth status: Poorest & - & - & - & - \\
\hline Wealth status: Poorer & $* 0.043$ & 0.738 & 0.550 & 0.991 \\
\hline Wealth status: Middle & $* 0.027$ & 0.702 & 0.514 & 0.960 \\
\hline Wealth status: Richer & 0.191 & 0.812 & 0.594 & 1.109 \\
\hline Wealth status: Richest & $* 0.020$ & 0.662 & 0.468 & 0.937 \\
\hline Parity: Primiparous & 0.245 & 0.745 & 0.454 & 1.223 \\
\hline Parity: Multiparous & - & - & - & - \\
\hline ANC: $<4$ times & - & - & - & - \\
\hline ANC: $\geq 4$ times & $* * *<0.001$ & 0.331 & 0.229 & 0.480 \\
\hline Childbirth assistance: Non-health worker & - & - & - & - \\
\hline Childbirth assistance:Health worker & 0.917 & 1.025 & 0.640 & 1.643 \\
\hline Place of delivery: Non-healthcare & - & - & - & - \\
\hline Place of delivery: Healthcare & 0.520 & 1.175 & 0.718 & 1.922 \\
\hline
\end{tabular}

Note: ${ }^{*} \mathrm{p}<0.05 ;{ }^{* *} \mathrm{p}<0.01 ;{ }^{* * *} \mathrm{p}<0.001$.

First, female worker mothers with the wealth status of the poorer category had 0.738 times the probability of experiencing neonatal death compared to the poorest (OR 0.738; 95\% CI 0.550-0.991). Female worker mothers with wealth status in the middle category had a probability of 0.702 times compared to the poorest to experience neonatal death (OR 0.702; 95\% CI 0.5140.960). Meanwhile, the richest female worker mothers had a probability of 0.662 times compared to the poorest to experience neonatal death (OR 0.662 ; 95\% CI 0.468 0.937).
Information on the results of this analysis indicates that poverty is one of the risk factors for neonatal death among female worker mothers in Indonesia. The same findings of information were also found in the previous studies $^{7,8}$. The results of the analysis informed that the richest group also had a risk of neonatal death, although the number was less than the other groups. This finding contradicts most studies which reveal that the low economic status (poorest, poorer, middle) is more at risk of neonatal mortality ${ }^{9-11}$. This information suggests that the economic status of the family, at any level, is likely to increase the risk of neonatal mortality. So that a more 
comprehensive program approach is needed to reduce neonatal mortality.

The reason female workers leave their children to return to work early after childbirth is the demand to make a living for their families ${ }^{12,13}$. This condition also explains a large number of neonatal mortality rates in the group of working mothers with the poorest, poorer, and poor economic status. The pressure to make a living is greater in this group. The provision of paid leave for working mothers is one of the initiatives in the neonatal mortality reduction program recommended by WHO and ILO. Output in the form of maternal and neonatal health levels was found to be better for working mothers who received paid maternity leave for longer ${ }^{14,15}$.

Second, female worker mothers who performed ANC completely ( $\geq 4$ times) were 0.331 times more likely than female worker mothers who performed ANC incompletely (OR $0.331 ; 95 \%$ CI $0.229-0.480$ ). The results of this analysis inform that doing ANC incompletely, or $<4$ times, is one of the risk factors for neonatal death among female worker mothers in Indonesia.

The findings of this analysis are in line with the recommendation of the Indonesian government which states that the ANC during pregnancy is done at least 4 times, namely in the first trimester 1 time, in the second trimester 1 time, and in the third trimester 2 times $^{16}$. This information also confirms the results of previous studies in several countries that ANC is a positive determinant for preventing neonatal death ${ }^{17-20}$. Meanwhile, a study in Afghanistan informed that ANC by skilled providers reduced the risk of neonatal death to 0.7 times compared to non-skilled providers ${ }^{21}$.

\section{Conclusions}

Based on the research results, it could be concluded that 2 factors are the risk factors for neonatal death among female worker mothers in Indonesia. These two factors were poverty and incomplete ANC.

It is recommended that the government issue a policy that can encourage companies that employ female worker mothers to facilitate the ANC process when they are pregnant, especially for poor female worker mothers. Working mothers in the formal sector need to be paid maternal leave for at least 12 weeks after giving birth to provide opportunities for mothers to care for their babies. For mothers working in the informal sector, it is necessary to think about providing a social safety net in the form of maternal cash benefits that can be implemented together with the National Health Insurance. This policy is needed to reduce neonatal death in Indonesia.

Acknowledgments: The author would like to thank the ICF International, who has agreed to allow the 2017 IDHS data to be analyzed in this article.

Source of Funding: Self-funding

\section{Conflict of Interests: Nil}

Ethical Clearance: The 2017 IDHS has passed ethical tests from the National Institute for Health Research and Development of the Indonesian Ministry of Health. The use of the 2017 IDHS data for this study has received permission from ICF International through its website: https://dhsprogram.com/data/new-userregistration.cfm.

\section{References}

1. SDG Indonesia 2030. Goal 03 SDGs (Tujuan 03 SDGs) [Internet]. 2020 [cited 2020 Aug 25]. p. 3. Available from: https://www.sdg2030indonesia. org/page/11-tujuan-tiga

2. UNICEF. Neonatal mortality. 2019.

3. World Health Organization. Newborns: reducing mortality [Internet]. 2019 [cited 2020 Aug 25]. p. 1. Available from: https://www.who.int/en/ news-room/fact-sheets/detail/newborns-reducingmortality

4. National Population and Family Planning Board, Statistics Indonesia, Ministry of Health, The DHS Program. Indonesia Demographic and Health Survey 2017 [Internet]. Jakarta; 2018. Available from: https://www.dhsprogram.com/pubs/pdf/ FR342/FR342.pdf

5. Faisal A. Factors Associated with Infant Mortality in Indonesia 2003-2007 (Faktor-Faktor Yang Berhubungan dengan Kematian Bayi di Indonesia Tahun 2003-2007). Universitas Indonesia Jakarta, Indonesia; 2010.

6. Wulandari RD, Laksono AD. Is parity a predictor of neonatal death in Indonesia? Analysis of the 2017 Indonesia demographic and health survey. Indian J Forensic Med Toxicol. 2020;14(3):2161-6.

7. Vijay J, Kumar Patel K. Risk factors of infant mortality in Bangladesh. Clin Epidemiol Glob 
Heal. 2020;8(1):211-4.

8. Morakinyo OM, Fagbamigbe AF. Neonatal, infant and under-five mortalities in Nigeria: An examination of trends and drivers (2003-2013). PLoS One. 2018;12(8):Article number e0182990.

9. Afshan K, Narjis G, Qureshi IZ, Cappello M. Social determinants and causes of child mortality in Pakistan: Analysis of national demographic health surveys from 1990 to 2013. J Paediatr Child Health. 2020;56(3):457-72.

10. $\mathrm{Lu}$ SSM, Stewart Williams J, Sommar JN. Inequalities in early childhood mortality in Myanmar - Association between parents' socioeconomic status and early childhood mortality. Glob Health Action. 2019;12(1):Article number 1603516.

11. Khajavi A, Pishgar F, Dehghani M, Naderimagham S. Socioeconomic inequalities in neonatal and postneonatal mortality: Evidence from rural Iran, 1998-2013. Int J Equity Health. 2017;16(1):Article number 83.

12. Baxter J. Is money the main reason mothers return to work after childbearing? J Popul Res. 2008;25:141-160.

13. Schmidt E-M, Rieder I. All about the money? Parents' justification patterns behind their parental leave arrangements. SWS - Rundschau. 2016;56(4):489-508.

14. Hewitt B, Strazdins L, Martin B. The benefits of paid maternity leave for mothers' post-partum health and wellbeing: Evidence from an Australian evaluation. Soc Sci Med. 2017;182(97-105).
Medico-legal Update, January-March 2021, Vol. 21, No. 1

15. Aitken Z, Garrett CC, Hewitt B, Keogh L, Hocking JS, Kavanagh AM. The maternal health outcomes of paid maternity leave: A systematic review. Soc Sci Med. 2015;130:32-41.

16. Laksono AD, Rukmini R, Wulandari RD. Regional disparities in antenatal care utilization in Indonesia. PLoS One. 2020;15(2):e0224006.

17. Laksono $\mathrm{AD}$, Wulandari $\mathrm{RD}$. Understanding Neonatal Death in Urban Area in Indonesia. Medico-Legal Updat. 2020;20(2):825-9.

18. Wulandari RD, Laksono AD. Antenatal Care as Predictor of Neonatal Death in Rural Indonesia. Int Med J [Internet]. 2020;25(2):511-8. Available from: https://www.seronijihou.com/article/ antenatal-care-as-predictor-of-neonatal-death-inrural-indonesia

19. Basha GW, Woya AA, Tekil AK. Determinants of neonatal mortality in Ethiopia: An analysis of the 2016 Ethiopia demographic and health survey. Afr Health Sci. 2020;20(2):715-23.

20. Mersha A, Bante A, Shibiru S. Neonatal mortality and its determinates in public hospitals of Gamo and Gofa zones, southern Ethiopia: Prospective follow up study. BMC Pediatr. 2019;19(1):Article number 499.

21. Kibria GMA, Burrowes V, Choudhury A, Sharmeen A, Ghosh S, Mahmud A, et al. Determinants of early neonatal mortality in Afghanistan: An analysis of the Demographic and Health Survey 2015. Global Health. 2018;14(1):Article number 47. 